\title{
Toxicidade dos corantes alimentares artificiais
}

Josiane Bizzi Schlemmer Braun, Rosane da Silva Rodrigues

https://doi.org/10.4322/mp.978-65-991393-3-8.c9

\section{Resumo}

Os corantes alimentícios são amplamente utilizados para conferir cor e tornar os alimentos mais atrativos. A utilização desses aditivos em alimentos, particularmente os corantes artificiais, vem sendo relacionada à ocorrência de reações adversas associadas ao seu consumo. O objetivo deste estudo foi realizar uma revisão bibliográfica sobre a toxicidade dos corantes alimentares artificiais. Realizou-se uma busca nas bases de dados nas plataformas online: Scientific Electronic Library Online (SCIELO), PUBMED e Literatura Latino-americana e do Caribe em Ciências da Saúde (LILACS) e Google Acadêmico, com publicações nacionais e internacionais relacionados ao tema. Foram selecionados artigos científicos, leis, portarias e resoluções, para integrar a presente revisão, datados de 1965 a 2019. Concluiu-se que os corantes alimentares artificiais, quando utilizados a longo prazo, podem causar danos à saúde do consumidor, com o desenvolvimento de enfermidades e ou outras complicações. É importante que as indústrias estejam atentas quanto ao uso dessas substâncias nos alimentos, respeitando os valores estabelecidos pela legislação, assim como os consumidores devem buscar informações de forma a não consumir o mesmo aditivo através de vários produtos, evitando ultrapassar a ingestão diária aceitável. Aspectos relacionados à rotulagem, com informações claras e de fácil compreensão, podem contribuir nestas escolhas.

Palavras-chave: aditivo alimentar, cor, efeitos colaterais, legislação.

\section{Introdução}

Corantes são aditivos alimentares que têm por finalidade melhorar o aspecto dos alimentos, transmitindo novas cores ou exaltando as que eles já possuem (SHIBAMOTO; BJELDANES, 2014). A aparência do produto é a maior justificativa para o emprego de corantes alimentícios (PRADO; GODOY, 2007), pois a cor do alimento tipifica-o e constitui-se em um fator fundamental para a aceitação do produto. Esta característica sensorial, embora subjetiva, é fundamental na indução da sensação global resultante de outras características, como o aroma, o sabor e a textura dos alimentos. Desta forma, a aparência do alimento pode exercer efeito estimulante ou inibidor do apetite (CONSTANT; STRINGHETA; SANDI, 2002).

A coloração é a primeira qualidade sensorial pelo qual os alimentos são julgados e, portanto, amplamente utilizada na indústria alimentícia para atender às expectativas dos consumidores, os quais usualmente associam cor ao sabor, ao aroma ou à qualidade do produto. O setor alimentício lança mão de diversos tipos de corantes que melhoram ou conferem a cor característica dos alimentos e bebidas, resultando em 
produtos que satisfaçam visualmente o consumidor, pois além de necessária para sobrevivência, a alimentação também é fonte de prazer e satisfação. Contudo, tem aumentado a preocupação quanto aos riscos toxicológicos desses produtos e ou seus metabólitos no organismo humano (CONSTANT; STRINGHETA; SANDI, 2002).

Os corantes são classificados em quatro classes: corante orgânico natural; corante orgânico sintético (artificial e idêntico ao natural); corante inorgânico e caramelo (BRASIL, 1977a; 1978). Na primeira metade do século XX, o uso de corantes artificiais na coloração de alimentos teve um grande crescimento em virtude de mudanças econômicas e pela descoberta de métodos de fabricação de corantes artificiais de forma eficaz e barata (BAFANA; DEVI; CHAKRABARTI, 2011). Entretanto, tem sido demonstrada a ocorrência de reações adversas associadas ao consumo de alimentos que contêm esses aditivos, incluindo desde urticárias, asmas e reações imunológicas, até câncer em modelos animais (BENTO; LIMA; PALM, 2015; LI et al., 2015). De acordo com Honorato et al. (2013), dentre as substâncias químicas genotóxicas utilizadas como aditivos alimentares, os corantes artificiais são considerados os mais genotóxicos, induzindo danos ao DNA (SHIBAMOTO; BJELDANES, 2014). Freitas (2012) e Moutinho et al. (2007) também demonstraram que os corantes artificiais foram capazes de ocasionar reações de hipersensibilidade, mutagênese $e$ carcinogênese por produzir, após ser metabolizado pela microflora intestinal, amina aromática e ácido sulfanílico, compostos com alto potencial cancerígeno.

Em virtude do aumento no número de compostos com poder corante e de seu uso estendido aos alimentos e bebidas, tornou-se necessário o controle de suas aplicações e surgiu uma maior preocupação com possíveis efeitos à saúde humana. Sob o ponto de vista toxicológico, estudos têm sido realizados para verificar os efeitos nocivos ao homem, particularmente associados aos corantes artificiais, devido às reações adversas que alguns consumidores podem apresentar (LUCOVÁ et al., 2013; PRADO; GODOY, 2003).

\section{Aditivo alimentar}

De acordo com a Portaria MS no 540/1997, aditivo alimentar é qualquer ingrediente adicionado intencionalmente aos alimentos, sem propósito de nutrir, mas com o objetivo de modificar as características físicas, químicas, biológicas ou sensoriais, durante a fabricação, processamento, preparação, tratamento, embalagem, acondicionamento, armazenagem, transporte ou manipulação de um alimento. Ao agregar-se poderá resultar em que o próprio aditivo ou seus derivados se convertam em um componente de tal alimento (BRASIL, 1997). Os aditivos alimentares possuem três características: são substâncias adicionadas aos alimentos e não podem ser consumidas sozinhas como alimento; incluem substâncias sintéticas e naturais; e o objetivo da adição é melhorar a cor, fragrância, sabor dos alimentos e atender às demandas de preservação, frescor e processamento (SUN; WANG, 2017).

Os aditivos comumente usados em alimentos são os antioxidantes, corantes, emulsificantes, estabilizadores, gelificantes, espessantes, conservantes, edulcorantes, entre outros, e alguns desses são úteis para aumentar o prazo de validade e impedir ou retardar alterações em alimentos causadas por micro-organismos ou enzimas (EFSA, 2013). É proibido o uso de aditivos em alimentos quando houver evidências ou suspeita de que o mesmo não é seguro para consumo pelo homem; interferir sensível e desfavoravelmente no valor nutritivo do alimento; servir para encobrir falhas no processamento e ou nas técnicas de manipulação, encobrir alteração ou adulteração da matéria-prima ou do produto já elaborado; induzir o consumidor a erro, engano ou confusão, e quando não estiver autorizado por legislação específica (BRASIL, 1997). 
Quanto à rotulagem dos aditivos nos alimentos, a Resolução RDC MS n 259/2002 determina que os aditivos devem ser declarados na lista de ingredientes. Essa declaração deve constar da função principal ou fundamental do aditivo no alimento; e seu nome completo ou seu número INS (Sistema Internacional de Numeração), ou ambos. Quando houver mais de um aditivo alimentar com a mesma função, pode ser mencionado um em continuação ao outro, agrupando-os por função. Os aditivos alimentares devem ser declarados depois dos ingredientes (BRASIL, 2002).

O uso dos aditivos deve ser limitado a alimentos específicos, em condições específicas e ao menor nível para alcançar o efeito desejado para que a ingestão do aditivo não supere os valores de ingestão diária aceitável (IDA) (BRASIL, 1997). Para a segurança do uso de corantes em alimentos, com exceção do corante Azul Patente $\mathrm{V}$, que ainda não teve a IDA determinada, ou seja, os dados toxicológicos disponíveis não são suficientes para se estabelecer a segurança de uso do mesmo, os demais possuem IDA nos valores expressos com base no peso corpóreo. Esse valor é uma estimativa realizada pelo grupo de especialistas da FAO/WHO (Food and Agricultural Organization/World Health Organization) do Comitê de Aditivos Alimentares (JECFA, Joint FAO/WHO Expert Committee on Food Additives), da quantidade de um determinado aditivo alimentar que pode ser ingerido diariamente por toda a vida, sem apreciável risco à saúde (JOINT FAO/WHO; JECFA, 2011). A soma das quantidades dos corantes utilizados nos alimentos não deverá ultrapassar a quantidade máxima correspondente ao corante permitido em maior quantidade, e a quantidade de cada corante não poderá ser superior ao seu limite individual. A Resolução CNNPA/MS n¹7/1977 estabelece esses limites de adição para os aditivos alimentares. O aditivo que não constar da legislação não tem permissão para ser utilizado em alimentos. Poderão ser empregados no mesmo alimento aditivos da mesma classe, desde que a quantidade total não ultrapasse o limite máximo autorizado para cada um, nem cada aditivo, isoladamente, ultrapasse o seu próprio limite, salvo restrições específicas que venham a ser fixadas (BRASIL, 1977b).

A RDC MS n45/2010 traz a relação dos aditivos para uso segundo as Boas Práticas de Fabricação (BPF). Um aditivo é considerado BPF quando possui IDA "não especificada". Isso significa que o uso está limitado à quantidade necessária para se obter o efeito tecnológico desejado (quantum satis), sempre que o aditivo não afetar a genuinidade do alimento. A autorização de um aditivo como BPF não significa que este pode ser utilizado em todos os alimentos. Somente poderá ser utilizado se estiver previsto no Regulamento Técnico especifico para a categoria de alimentos correspondente, geralmente com a frase "todos os autorizados como BPF" para a determinada função (BRASIL, 2010).

A autorização do uso de aditivos é concedida mediante a demonstração de inocuidade para o consumidor, através da realização de estudos toxicológicos e da demonstração da sua necessidade tecnológica (ROMIERO; DELGADO, 2013). A utilização dos aditivos está sujeita a controles rigorosos, considerando que o consumo excessivo pode causar reações adversas, quer seja crônica ou aguda, como também reações tóxicas (TOMASKA; BROOKE-TAYLOR; 2014). Os estudos toxicológicos apontam diversos efeitos negativos, em decorrência das propriedades químicas e de produtos de metabolização (DOWNHAM; COLLINS, 2000). Portanto, deve ser feita a adequada avaliação toxicológica, considerando os efeitos que determinado aditivo pode vir a causar durante o consumo prolongado, levando em conta, entre outros aspectos, qualquer efeito cumulativo, sinérgico e de proteção, decorrente do seu uso. Os aditivos alimentares devem ser mantidos em observação e reavaliados sempre que necessário caso se modifiquem as condições de uso. Em relação aos corantes, o estudo toxicológico é realizado com os corantes que atendam às especificações da 
FAO/WHO ou do Food Chemicals Codex, portanto é muito importante a análise destes antes da adição aos alimentos (MARTINS, 2014).

Os resultados adversos associados aos aditivos alimentares incluem vários efeitos inespecíficos, de início tardio e ou local, como alterações no peso corporal, por exemplo (KRAMER et al., 2019). A maioria dos efeitos provavelmente não tem impacto na saúde e alguns ainda podem ser benéficos, como os efeitos antimicrobianos e antioxidantes. No entanto, alguns resultados preocupantes surgiram em relação a vários aditivos, como nitratos/nitritos (ETEMADI et al., 2017; QUIST et al., 2018), glutamato (ATASEVEN et al., 2016; CHAKRABORTY, 2019), edulcorantes (AZAD et al., 2017; SOFFRITTI, et al., 2016), emulsificantes (VIENNOIS; CHASSAING, 2018; VIENNOIS et al., 2017), corante caramelo (SMITH et al., 2015), dióxido de titânio $\left(\mathrm{TiO}_{2}\right)$ (BETTINI et al., 2017), entre outros, os quais foram previamente associados a perturbações metabólicas, microbianas do intestino ou endócrinas, juntamente com efeitos de estresse carcinogênico, inflamatório e ou oxidativo. Além disso, alguns resultados experimentais sugerem que diferentes aditivos podem interagir (entre si e ou com a matriz alimentar) e assim levar a efeitos sinérgicos ou antagonistas, mas poucos estudos foram realizados sobre esse tema até o momento (MOUBARAC et al., 2017).

Sasaki et al. (2002) determinaram a genotoxicidade de 39 substâncias químicas utilizadas como aditivos alimentares. De todos os aditivos, os corantes artificiais (amaranto, vermelho allura, ponceau 4R, tartrazina, eritrosina, rosa bengala e floxina B) foram os mais genotóxicos, induzindo danos ao DNA nos órgãos do trato gastrointestinal com dose baixa (10 ou $100 \mathrm{mg} / \mathrm{kg}$ de peso corpóreo). Entre os corantes artificiais analisados, o amaranto, o vermelho allura, o ponceau $4 \mathrm{R}$ e a tartrazina induziram danos ao DNA no cólon próximo às ingestões diárias aceitáveis (IDAs). Chemin e Milito (2007) também relataram que os corantes estão comprovadamente associados a alergias, crises de asmas, ansiedade e até quadros de depressão, em casos de intoxicação severa. Os corantes apresentam efeitos agudos em curto prazo, já que o consumo dos mesmos pode apresentar, de modo geral, alergias de pele, urticária, hiperatividade em crianças e em longo prazo a possibilidade de evolução das mesmas, podendo desenvolver distúrbios comportamentais, emocionais e sociais (GUIMARÃES, 2010). Tumores de bexiga, fígado e rins, surgimento de asma, eczema, dermatite de contato, irritação dos olhos, aberrações cromossomais são alguns exemplos de reações adversas do consumo de corantes artificiais (CHUNG, 2016).

\subsection{Corantes Alimentícios}

De acordo com a Resolução MS no 44/77, considera-se corante a substância ou a mistura de substâncias que possuem a propriedade de conferir ou intensificar a coloração de alimento (e bebida) (BRASIL, 1977a). O emprego dos corantes também está regulamentado pelo Decreto $n^{\circ} 55.871 / 1965$, que determina que seja tolerada a venda de mistura ou solução de, no máximo, três corantes e que deverá constar da rotulagem da mistura ou da solução posta à venda a sua composição qualitativa e quantitativa (BRASIL, 1965). Além dessas, a Resolução MS nº 37/1977 considera laca o sal preparado a partir do corante, em combinação com o radical básico de alumínio ou cálcio, devendo ser exposto à venda sob o nome "LACA" (alumínio ou cálcio), seguido do nome comum do corante utilizado (BRASIL, 1977c).

Os corantes possuem o atributo de conceder ou intensificar a coloração de alimentos, tornando-os mais atrativos, influenciando o poder de escolha do consumidor, sendo um fator importante para o mercado (PARMAR; SINGH, 2018; ROVINA et al., 2016). 
As cores são capazes de influenciar as decisões do dia-a-dia, principalmente, as que envolvem os alimentos. Aparência, segurança, características sensoriais e aceitabilidade dos alimentos são todas afetadas pela cor (CLYDESDALE, 1993; DOWNHAM; COLLINS, 2000). A cor pode afetar outras características sensoriais e essa inter-relação pode influenciar no aceite ou não do alimento. Isso pode estar associado ao fato do ser humano "enxergar" sabores através da cor (CLYDESDALE, 1993).

A cor influencia na percepção do sabor, na aceitabilidade e, consequentemente, na preferência por certos alimentos e bebidas. Isso é um problema para as indústrias, pois a relação causa-efeito não pode ser ignorada ou minimizada nas formulações de novos alimentos e bebidas que visam suprir as necessidades do ser humano (CLYDESDALE,1993; DOWNHAM; COLLINS, 2000). A determinação da cor de um corante depende da sua estrutura química, na qual a distribuição eletrônica entre os grupos funcionais e cadeia de átomos determina a emissão de uma determinada faixa de cor proveniente da reflexão da radiação visível (luz) (BAFANA; DEVI; CHAKRABARTI, 2011; MARTÍNEZ SUÁREZ, 2017).

Do ponto de vista nutricional, o uso de corantes alimentícios não é necessário. Sua função é apenas colorir os alimentos fazendo com que os produtos industrializados tenham uma aparência mais parecida com a dos produtos naturais, sendo, portanto, mais agradável aos olhos do consumidor, e seu uso, exclusivamente estético, é primordialmente justificado por motivos comerciais. Eles são extremamente comuns, já que a cor e a aparência têm um papel importantíssimo na aceitação dos produtos pelo consumidor (COSENTINO, 2005; CUNHA, 2008).

Segundo a Resolução MS no 44/1977, modificada pela Resolução MS no 11/1978, os corantes são classificados em: corante orgânico natural (aquele obtido a partir de vegetal, ou eventualmente, de animal, cujo princípio corante tenha sido isolado com o emprego de processo tecnológico adequado); corante orgânico sintético (aquele obtido por síntese orgânica mediante o emprego de processo tecnológico adequado), sendo subdividido em corante artificial (não encontrado em produtos naturais) e corante idêntico ao natural (cuja estrutura química é semelhante à do princípio ativo isolado de corante orgânico natural, incluindo o caramelo - processo amônia, obtido pelo processo amônia, desde que o teor de 4-metil, imidazol não exceda no mesmo a 200 $\mathrm{mg} / \mathrm{kg}$ ); corante inorgânico (aquele obtido a partir de substâncias minerais e submetido a processos de elaboração e purificação adequados a seu emprego em alimento); e o caramelo (corante natural obtido pelo aquecimento de açúcares à temperatura superior ao ponto de fusão) (BRASIL, 1977a, 1978).

Esta revisão bibliográfica abordará apenas os corantes artificiais.

\subsubsection{Corantes Artificiais}

Os corantes artificiais são uma classe de aditivos sem valor nutritivo, introduzidos nos alimentos e bebidas com o único objetivo de conferir cor, tornando-os mais atrativos. Por esse motivo, do ponto de vista da saúde, os corantes artificiais em geral não são recomendados, justificando seu uso quase que exclusivamente do ponto de vista comercial e tecnológico. Mesmo assim, os corantes são amplamente utilizados nos alimentos e bebidas devido à grande importância na aceitação dos produtos (PRADO; GODOY, 2003).

Os corantes artificiais apresentam algumas vantagens tecnológicas em relação aos naturais, como por exemplo, serem muito mais fáceis de usar, e são geralmente mais resistentes ao tratamento térmico, $\mathrm{pH}$ extremo e luz, que os corantes naturais 
(CALVO, 2006). Em contrapartida, os corantes artificiais podem causar riscos à saúde, e geralmente estão associados ao modo e ao tempo de exposição, podendo-se destacar alguns problemas como alergias, rinite, broncoconstrição, hiperatividade, danificação cromossômica, tumores, entre outros (MARMITT; PIROTTA; STÜLP, 2010).

A legislação brasileira permite o uso de 14 corantes artificiais: tartrazina, amarelo crepúsculo, bordeaux $S$ ou amaranto, ponceau $4 \mathrm{R}$, eritrosina, vermelho 40 , indigotina, azul brilhante, azorrubina, azul patente $\mathrm{V}$, verde sólido, amarelo de quinoleína, negro brilhante e marrom HT, junto com o seu número INS e valores de IDA (BRASIL, 1988, 1999, 2005). Existe um consenso dessa legislação entre os países membros do MERCOSUL, no que se refere ao uso de corantes em alimentos. A Resolução GMC (Grupo Mercado Comum) $n^{\circ}$ 50/1997 trata dessa harmonização, bem como a Resolução GMC n 52/1998, que se refere aos critérios para determinar funções dos aditivos e seus máximos para todas as categorias de alimentos.

Os corantes artificiais podem ser classificados de acordo com sua função química em quatro classes de corantes: azo, trifenilmetanos, indigóides e xantenos. A classe "azo", o maior grupo de aditivos dessa categoria, representando $70 \%$ dos corantes produzidos no mundo, são classificados e conhecidos pela presença de uma dupla ligação entre nitrogênios no meio da molécula (-N=N-) (GARCIA-SEGURA et al., 2013). Suspeita-se que a parte ativa da molécula causadora de tumores seja formada pela sua degradação. Desde o início do século $X X$ tem sido demonstrado que moléculas originadas dos corantes azoicos apresentam ação cancerígena, principalmente pela formação do amino - azobenzeno (LEHMANN, 1970). Os corantes azos compreendem o corante amaranto, amarelo crepúsculo, azorrubina, ponceau 4R, tartrazina, marrom HT, negro brilhante, amarelo de quinoleína e o vermelho 40 . Todos os corantes desse grupo apresentam boa estabilidade à luz, calor e ácido. Os corantes amaranto, ponceau 4R, tartrazina e amarelo crepúsculo apresentam descoloração na presença de agentes redutores como o ácido ascórbico e o dióxido de enxofre (MENDONÇA, 2011).

A classe trifenilmetanos apresenta estrutura básica de três radicais arila, em geral grupos fenólicos, ligados a um átomo de carbono central e apresentam, ainda, grupos sulfônicos que lhes conferem alta solubilidade em água (PRADO; GODOY, 2003). Os corantes que pertencem a essa classe são: azul patente $\mathrm{V}$, que possui excelente estabilidade à luz, calor e ácido, mas apresenta descoloração na presença de ácido ascórbico e dióxido de enxofre; verde rápido tem razoável estabilidade à luz, calor e ácido, mas possui baixa estabilidade oxidativa; e o azul brilhante apresenta as mesmas características do verde rápido (GODOY; PRADO, 2003)

A classe de corante indigoide possui estrutura molecular complexa, o que o torna mais estável quimicamente e mais resistente aos processos de biodegradação e de remoção mais comumente utilizados para tratamento de efluentes. Faz parte dessa classe o indigotina que apresenta baixa estabilidade à luz, calor e ácido, baixa estabilidade oxidativa e descolore na presença de dióxido de enxofre e ácido ascórbico (GODOY; PRADO, 2003).

A classe de corante xanteno possui a eritrosina que é insolúvel em pH abaixo de 5 . É o único representante dessa classe no Brasil (GODOY; PRADO, 2003).

A seguir serão descritos os corantes artificiais permitidos no Brasil, sendo eles apresentados pelo nome usual, seguido de seu número INS. 


\subsubsection{Amaranto ou Bordeaux S (E123)}

O amaranto é um corante de cor vermelho magenta que possui tonalidades que variam entre o vermelho escuro, o roxo e o marrom. Utilizado na indústria de alimentos por sua boa estabilidade ao calor, luz e acidez, apesar de ser degradado na presença de ácido ascórbico e dióxido de enxofre (DOWNHAM; COLLINS, 2000; MPOUTOUKAS et al., 2010). Consiste em um monoazo sulfonado, com o nome 2hidróxi-1-(4-sulfonato-1-naftilazo) naftaleno-3,6-dissulfonato trissódio (Figura 1). É usado em balas, produtos de pastelaria, licores (ROcío, 2013), sorvetes, misturas para bolo, sopas, cereais, molhos para saladas, gomas de mascar, chocolate e café (MPOUNTOUKAS et al., 2010).

Sobre a toxicologia do amaranto, especialmente a respeito da genotoxicidade e carcinogenicidade da substância, estudos demonstraram, de forma geral, resultados divergentes (MPOUNTOUKAS et al., 2010; SARIKAYA; SELVI; ERKOÇ, 2012; TSUDA et al., 2001). Sarikaya, Selvi e Erkoç (2012) usaram diferentes concentrações do corante (12,5, 25 e $50 \mathrm{mg} \mathrm{mL}^{-1}$ em meio de cultura padrão de Drosophila melanogaste) e foi verificado dano ao DNA, sendo que somente para a concentração mais baixa obteve-se dados inconclusivos para a genotoxicidade. Alguns trabalhos executaram a técnica do ensaio cometa para verificar a genotoxicidade do amaranto, os quais obtiveram resultados positivos (SASAKI et al., 2002; SHIMADA et al., 2010; TSUDA et al., 2001). Shimada et al. (2010) verificaram que o amaranto é genotóxico para células do cólon de camundongos. Estudo similar foi realizado anteriormente por Sasaki et al. (2002), que puderam verificar dano ao DNA não somente do cólon, mas também do estômago e bexiga de camundongos. Hashem et al. (2010) também mostraram alterações nas células de defesa de ratos e concluíram que a resposta imunológica dos animais se alterou em presença do corante no organismo. Desde 1976 seu uso foi proibido na Áustria, EUA, Noruega e Rússia, devido à suspeita de carcinogenicidade e toxicidade para embriões (SARIKAYA; SELVI; ERKOÇ, 2012). De acordo com o JECFA (2006) sua IDA é de 0-0,5 mg/kg de peso corpóreo (BRASIL, 2016).

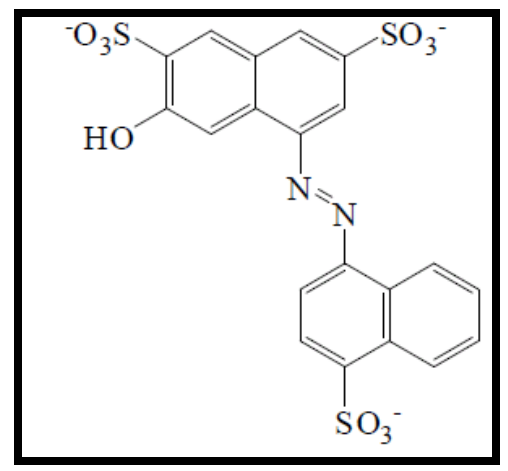

Figura 1. Estrutura química do corante amaranto.

Fonte: ISENMANN, 2014.

\subsubsection{Amarelo crepúsculo (E110)}

O amarelo crepúsculo é utilizado em alimentos para garantir cores que variam do laranja ao vermelho. Possui boa estabilidade quando exposto à luz e variações de temperatura e pH (DOWNHAM; COLLINS, 2000). Consiste em um monoazo sulfonado, de nome 2-hidróxi-(4-sulfonatofenilazo) naftaleno-6-sulfonato (Figura 2). A presença dos dois grupos sulfonados garante ao corante uma boa solubilidade em água (ROVINA et al., 2016). É utilizado na preparação de doces e balas, queijos, geleias, sopas industrializadas, marmeladas, sorvetes, refrigerantes e bebidas 
energéticas, camarões industrializados, sobremesas congeladas e suplementos alimentares, o que o coloca como o terceiro corante mais usado no mundo (GOMEZ et al., 2016; KOBYLEWSKI; JABOBSON, 2010).

Quanto à toxicologia, a genotoxicidade do amarelo crepúsculo tem sido discutida na literatura, uma vez que sua azorredução determina a formação de aminas aromáticas sulfonadas, que foram classificadas como de baixo potencial para causar dano ao DNA. Esse fato é considerado até mesmo por alguns órgãos reguladores do uso de aditivos alimentares, como a Autoridade Europeia em Segurança Alimentar (European Food Safety Autority - EFSA) (AMCHOVA; KOTOLOVA; RUDA-KUCEROVA, 2015 KÖNIG, 2015). Contudo, esse corante apresentou efeito citotóxico e perturbação nos processos de proliferação e expressão de moléculas de defesa em esplenócitos e diminuição no peso do timo e na contagem de linfócitos e monócitos de ratos. Apontou também o desenvolvimento de transtorno por déficit de atenção com hiperatividade (TDAH) em crianças, assim como citotoxicidade e perturbação da proliferação de linfócitos humanos (AMCHOVA; KOTOLOVA; RUDA-KUCEROVA, 2015; ARNOLD; LOFTHOUSE; HURT, 2012; DWIVEDI; KUMAR, 2015; HASHEM et al., 2010; KOBYLEWSKI; JABOBSON, 2010; KUS; EROGLU, 2015; YADAV et al., 2013;). Freitas (2012) e Polônio (2010) também demonstraram em seus estudos que o corante amarelo crepúsculo foi capaz de desencadear reações como angioedema, vasculite, púrpura e choque anafilático. De acordo com o JECFA (2011) sua IDA é de 0-4 mg/kg de peso corpóreo (BRASIL, 2016).

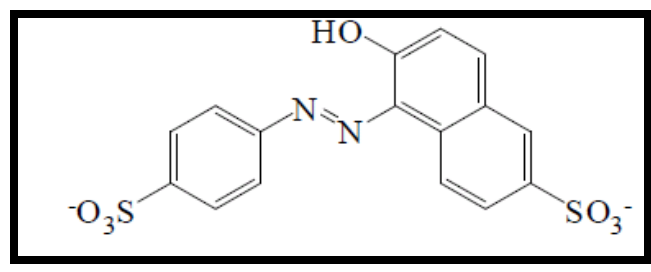

Figura 2. Estrutura química do corante amarelo crepúsculo. Fonte: ISENMANN, 2014.

\subsubsection{Azorrubina (E122)}

O corante azorrubina confere coloração vermelho-amarronzada. Nome químico sal dissódio-4-hidróxi-3-[(4-sulfo-1-naftalenil) azo]-1-naftaleno sulfonato (Figura 3). Possui boa estabilidade à acidez, luz e calor (DOWNHAM; COLLINS, 2000). É utilizado em vários alimentos, como produtos de padaria, bebidas, doces, gelatinas, iogurtes, pudins instantâneos, entre outros (AMIN; HAMEID II; ELSTTAR, 2010; BASU; KUMAR, 2014). Tem papel fundamental na indústria para a manutenção da cor de bebidas como sucos de romã ou de uva, uma vez que as substâncias naturais que dão coloração a esses produtos, as antocianinas, podem ser degradadas no processamento (GHASEMPOUR et al., 2017).

A toxicologia da azorrubina vem sendo estudada por ser um corante azo, e também por alguns efeitos adversos, como prejuízo no funcionamento renal e hepático, perda de peso e agravo no desenvolvimento de animais (AMIN; HAMEID II; ELSTTAR, 2010) e ligação com consequente perda de função da albumina sérica (BASU; KUMAR, 2014; MASONE; CHANFORAN, 2015). Basu e Kumar (2015) também demonstraram a capacidade de ligação da azorrubina com moléculas de hemoglobina, e foi relatado que o corante modifica a estrutura da molécula da hemoglobina alterando a capacidade de transporte de substâncias, especialmente o oxigênio. Segundo Amchova, Kotolova e Ruda-Kucerova (2015) poucos estudos foram capazes de 
detectar potencial genotóxico relevante para a azorrubina. De acordo com o JECFA (2006) sua IDA é de 0-4 mg/kg de peso corpóreo (BRASIL, 2016).

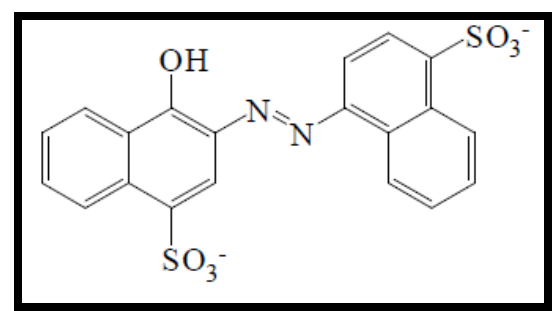

Figura 3. Estrutura química do corante azorrubina.

Fonte: ISENMANN, 2014.

\subsubsection{Ponceau 4R (E124)}

O corante ponceau 4R também é chamado de "vermelho cochonilha $A$ ", cujo nome químico é sal trissódio de (1-(4-sulfo1-naftilazo)-2-naftol-6,8-disulfonato (Figura 4). Sua estrutura química corresponde a duas frações de naftaleno mono e bissulfonados, unidos por uma ligação azo. É instável à presença de ácido ascórbico e dióxido de enxofre, mas é considerado resistente à acidez, calor e pH. Além de corante alimentício, é utilizado também em cosméticos e medicamentos (DOWNHAM; COLLINS, 2000). Como corante é utilizado principalmente em bebidas, coberturas e misturas para bolo, devido ao seu baixo valor comercial, boa estabilidade e solubilidade (KONIG, 2015; ZHANG et al., 2017). Utilizado para dar cor "morango" a balas e produtos de pastelaria, sorvetes, e também em substitutos de caviar e derivados de carne (CALVO, 2006).

Foi constatado genotoxicidade em células do cólon e alterações neurocomportamentais e de memória espacial em ratos. Estudos ainda apontaram alterações comportamentais no desenvolvimento de TDAH em crianças (ARNOLD; LOFTHOUSE; HURT, 2012; TANAKA, 2001; MCCANN et al., 2007; TSUDA et al., 2001). Ponceau $4 R$ também ocasionou casos de alergia, que estiveram relacionados a pessoas com sensibilidade a esse tipo de reação imunológica (FEKETEA; TSABOURI, 2017). De acordo com o JECFA (2011) sua IDA é de 0-4 mg/kg de peso corpóreo (BRASIL, 2016).

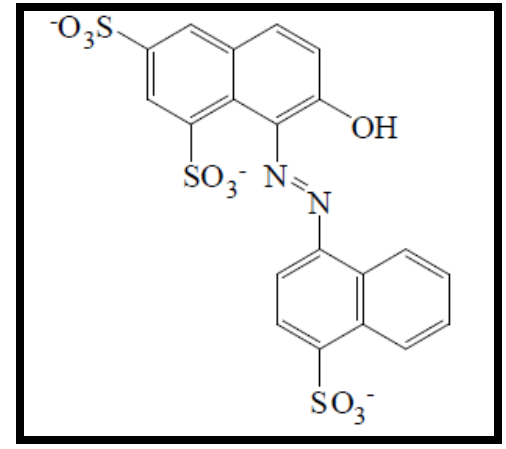

Figura 4. Estrutura química do corante ponceau 4R.

Fonte: ISENMANN, 2014. 


\subsubsection{Vermelho 40 (E129)}

Esse corante é utilizado desde a década de 80, principalmente nos Estados Unidos, onde foi introduzido para substituir o corante amaranto (CALVO, 2006). O corante vermelho 40, também conhecido como vermelho allura, é um corante azo, possui uma coloração que tende ao vermelho escuro e ao marrom (ABDULLAH et al., 2008). Nome químico sal dissódio de 6-hidróxi-5-[(2-metóxi-5-metil-4-sulfofenil) azo]-2napftaleno sulfonato (Figura 5). A presença de dois grupos sulfonados o torna bastante solúvel em água, sendo pouco absorvido no trato gastrointestinal (TSUDA et al., 2001). É resistente ao calor, luz e pH (PRADO; GODOY, 2003). É utilizado em alimentos e bebidas, como refrigerantes, gelatinas, produtos lácteos, pudins, condimentos, xaropes, doces, cereais e suplementos alimentícios (BASTAKI et al., 2017; POURREZA; RASTEGARZADEH; LARKI, 2011; WU et al., 2015).

A toxicologia do corante vermelho 40 é muito abordada na literatura, e vários testes in vitro foram realizados a fim de avaliar sua genotoxicidade, porém não foram observados efeitos negativos (BASTAKI et al., 2017). Segundo Feketea e Tsabouri (2017), não foram relatados casos de reação alérgica em crianças. No entanto, um estudo com neutrófilos humanos constatou que o aditivo aumenta a produção de mediadores inflamatórios através dessas células, que pode estar relacionada a respostas alérgicas e doenças como asma e artrite reumatoide (LEO et al., 2017). Tsuda et al. (2001) avaliaram o dano ao DNA causado pelo corante e constataram que o epitélio do cólon foi a parte mais afetada. Shimada et al. (2010) confirmaram este dano ao epitélio do cólon. Arnold, Lofthouse e Hurt (2012) também sugerem que o vermelho 40 pode ter efeitos sobre o cérebro de crianças mesmo sem cruzar a barreira hematoencefálica, contribuindo para o transtorno por déficit de atenção com hiperatividade e outras doenças. Ainda, foi demonstrado um efeito inibitório da enzima humana anidrase carbônica II, sendo que sua inibição causa diminuição do pH e dilatação vascular, o que pode resultar em doenças como a osteoporose e a acidose renal tubular (ESMAEILI et al., 2016; KHODARAHMI; ASHRAFI-KOOSHK; KHALEDIAN, 2015). De acordo com o JECFA (2006) sua IDA é de 0-7 mg/kg peso corpóreo (BRASIL, 2016).

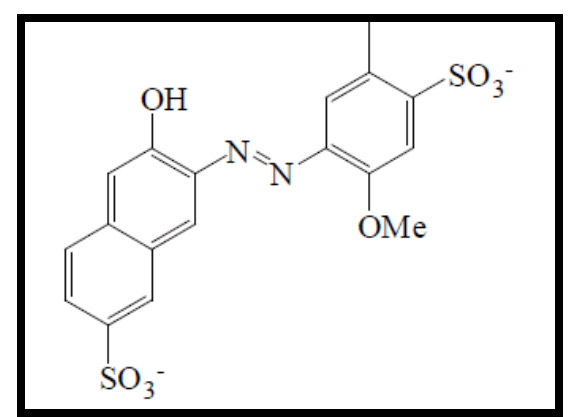

Figura 5. Estrutura química do corante vermelho 40.

Fonte: ISENMANN, 2014.

\subsubsection{Tartrazina (E102)}

A tartrazina é um corante azo, nome químico sal trissódio de 4,5-dihidro-5-oxo-1-(4sulfofenil)-4-[4-sulfofenil-azo]-1H-pirazol-3-carboxilato (Figura 6). Possui boa solubilidade em água, é estável a variações de $\mathrm{pH}$, luz e oxigênio (AL-SHABIB et al., 2017; JIANG et al., 2014). É o menos tóxico dentre os corantes sintéticos (SHIBAMOTO; BJELDANES, 2014). Dá aos alimentos e bebidas uma tonalidade amarela mais ou menos alaranjada, dependendo da quantidade adicionada. É utilizado 
em suplementos alimentares e alimentos como sorvetes, bolos, balas e confeitos, salgadinhos de batata, refrigerantes, bebidas alcoólicas, chicletes, gelatina, entre outros (AL-SHABIB et al., 2017; BASTAKI et al., 2017).

Em relação à toxicologia, esse corante está relacionado com diversas reações de hipersensibilidade como urticária, asma, náusea, anafilaxia, vômitos, dermatite, dor de cabeça, eczema, angioedema, bronquite, rinite e broncoespasmos. Em doses elevadas induz à lesão no DNA em estômago, cólon e bexiga urinária possibilitando o surgimento de câncer em longo prazo (FREITAS, 2012; BRASIL, 2007). Além disso, pode desencadear hipercinesia, distúrbios de comportamento e eosinofilia (POLÔNIO, 2010). Em casos raros, a tartrazina pode inibir a agregação plaquetária interferindo na coagulação sanguínea (PRADO; GODOY, 2003). Também há relatos de reações alérgicas, hiperatividade em crianças, genotoxicidade, tumor de tireoide, TDAH e urticária (AL-SHABIB et al., 2017), assim como alterações nos marcadores de função hepática (AMIN; HAMEID II; ELSTTAR, 2010). De acordo com o JECFA (2006) sua IDA é de 0-7,5 mg/ kg de peso corpóreo (BRASIL, 2016).

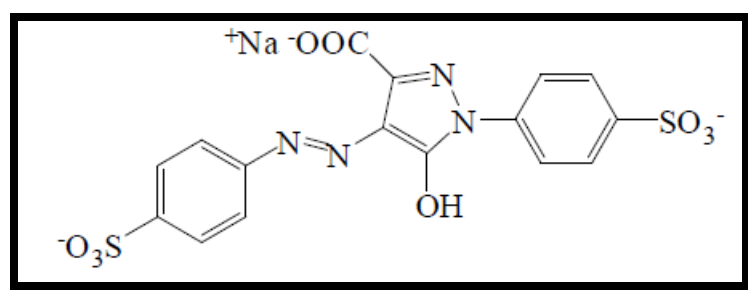

Figura 6. Estrutura química do corante tartrazina.

Fonte: ISENMANN, 2014.

\subsubsection{Marrom HT (E155)}

O corante marrom HT é usado para adicionar vários tons de marrom aos alimentos. Caracteriza-se por um composto diazo com dois grupos sulfônicos, tendo seu nome químico de 4,4'-(2,4-dihidróxi-5-hidroximetil-1,3-fenileno diazo) di-(naftaleno-1sulfonato) (Figura 7). É estável à luz, calor e acidez (DOWNHAM; COLLINS, 2000; HONG et al., 2014). É utilizado em bebidas não alcoólicas, vegetais em conserva, produtos de padaria como biscoitos e bolos, decorações e coberturas, queijos, iogurtes, geleias, patês de carne ou peixe, molhos, suplementos alimentícios, sopas, entre outros (HONG et al., 2014; KHATUN et al., 2017).

Em relação à toxicidade, Konig (2015) relatou que não foi observada a toxicidade do corante marrom HT em estudos com ratos na concentração de até $715 \mathrm{mg} / \mathrm{kg}$ de peso corporal. Porém, Bawazir (2012) demonstrou que o corante marrom HT pode ocasionar susceptibilidade do cérebro ao estresse oxidativo, assim como alterou significativamente os níveis dos marcadores bioquímicos da função dos órgãos, como a aspartato aminotransferase (AST) e a alanina aminotransferase (ALT). Em um experimento com ratas, foi avaliado a função ovariana e parâmetros hematológicos, e foi constatada uma redução significativa nos ciclos reprodutivos dos animais, assim como uma redução de enzimas antioxidantes (KHATUN et al., 2017). De acordo com o JECFA (2006) sua IDA é de 0-1,5 mg/kg de peso corpóreo (BRASIL, 2016). 


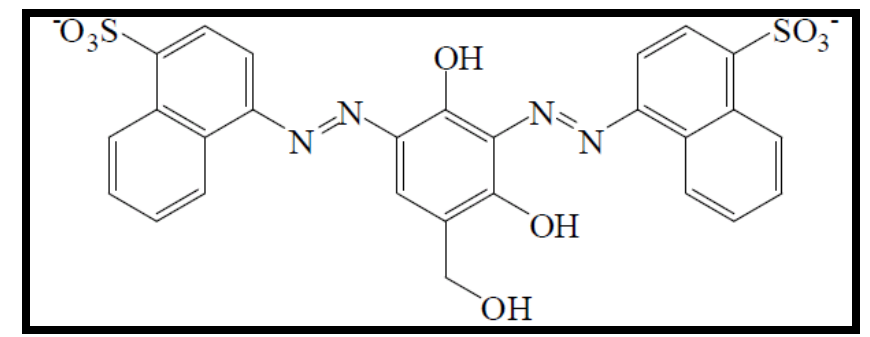

Figura 7. Estrutura química do corante marrom HT.

Fonte: ISENMANN, 2014.

\subsubsection{Negro brilhante BN (E151)}

O negro brilhante BN é um corante diazo, conferindo aos alimentos cores escuras, que podem ir do violeta ao azul marinho, dependendo da mistura com outros corantes (DOWNHAM; COLLINS, 2000; PASIAS; ASIMAKOPOULOS; THOMAIDIS, 2015). Possui nome químico 4-acetamido-5-hidróxi-6-[7-sulfonato-4-(4-sulfonatofenilazo)-1naftilazo] naftaleno-1,7-disulfonato (Figura 8). Apresenta boa estabilidade à luz, entretanto, é vulnerável ao calor e compostos redutores ou oxidantes presentes nos alimentos (DOHNHAM; COLLINS, 2000; KÖNIG, 2015). É utilizado na fabricação de gelatinas, molhos marrons, misturas para bolos (MACIOSZEK; KONONOWICZ, 2004). Em relação à toxicologia, Macioszek e Kononowicz (2004), em um estudo com linfócitos humanos observaram que o corante negro brilhante BN foi capaz de causar danos ao DNA. Também parece afetar algumas pessoas alérgicas à aspirina e também asmáticos (CALVO, 2006). De acordo com o JECFA (2006) sua IDA é de 0-1 $\mathrm{mg} / \mathrm{kg}$ de peso corpóreo (BRASIL, 2016).

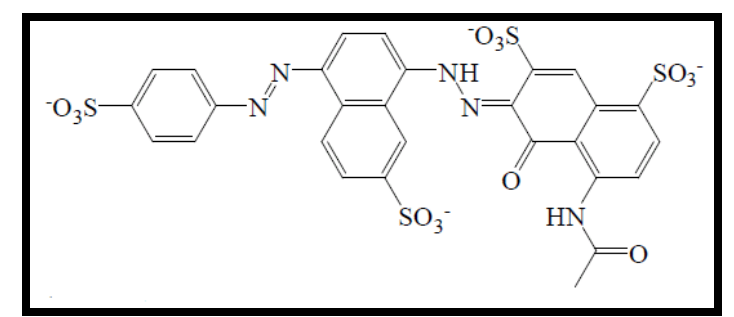

Figura 8. Estrutura química do corante negro brilhante BN.

Fonte: ISENMANN, 2014.

\subsubsection{Eritrosina (E127)}

O corante eritrosina é sintetizado a partir da tinta do alcatrão e seu nome químico consiste de um sal di-sódico 2,4,5,7-tetraiodo fluoresceina (Figura 9) (PRADO; GODOY, 2003). É o único representante no Brasil da classe de corantes xanteno, caracterizado por uma forte absorção de luz, apresenta a capacidade de iniciar reações fotoquímicas, possuindo elevada capacidade fotodinâmica (SPELLMEIER; STÜLP, 2009; YASSUNAKA et al., 2015). Por isso, sua principal desvantagem do ponto de vista tecnológico é que é relativamente sensível à ação da luz (RÓCIO, 2013). É utilizado em sobremesas, compotas (principalmente de morango), derivados de carne, patês de atum ou salmão, bebidas, biscoitos, doces, produtos de padaria, chicletes e sorvetes, entre outros (RÓCIO, 2013; SPELLMEIER; STÜLP, 2009).

Quanto à toxicologia, estudos mostram que a eritrosina pode causar reações alérgicas nos olhos, irritação na pele, membrana mucosa e nas vias aéreas superiores, dores de 
cabeças severas e náusea (DOWNHAM; COLLINS, 2000; MITTAL et al., 2006; TANAKA, 2001; UYSAL; ARAL, 1998). Segundo Netto (2009), a eritrosina pode ser fototóxico, pois contém $557 \mathrm{mg}$ de iodo por grama de produto, sendo que seu consumo excessivo pode causar aumento de hormônio tireoidano no sangue em níveis capazes de ocasionar hipertireoidismo. Corroborando, estudos também relatam que a eritrosina em doses muito altas produz alterações na tireoide, o que pode, em alguns casos, até levar ao desenvolvimento de tumores (CALVO 2006; PRADO; GODOY, 2003; STEFANI et al., 2009). Também há relatos na literatura de fotossensibilidade, eritrodermia, descamação, broncoespasmo e um possível efeito carcinogênico (STEFANI et al., 2009), assim como alterações no comportamento humano (POLÔNIO; PERES, 2009). Devido às suas características tóxicas e carcinogênicas, são realizados processos para promover sua remoção de águas residuais (MITTAL et al., 2006). De acordo com o JECFA (2006) sua IDA é de 0-0,1 $\mathrm{mg} / \mathrm{kg}$ de peso corpóreo (BRASIL, 2016).

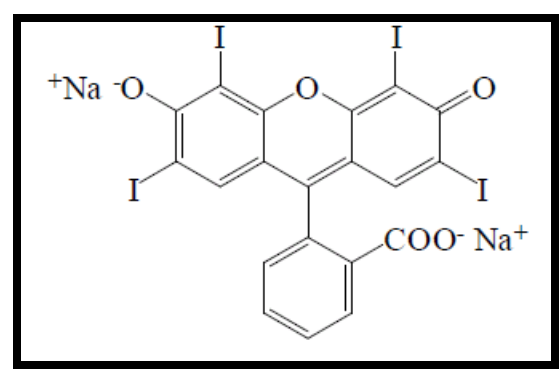

Figura 9. Estrutura química do corante eritrosina.

Fonte: ISENMANN, 2014.

\subsubsection{Indigotina (E132)}

O corante indigotina, também chamado de "indigo carmina", é o único representante da família de corantes conhecidos como "indigoides" que pode ser legalmente usado para colorir alimentos (CALVO, 2006). Quimicamente, consiste em um 3,3 'dioxo[delta2, 2'-biindoline] -5,5'-dissulfonato (Figura 10). É um corante sintético derivado de um corante natural extraído de folhas das plantas Indigofera tinctoria L., Indigofera suffruticosa Mill ou Indigofera arrecta Hochst. ex A. Rich. Tem baixa estabilidade oxidativa ao calor, luz e ambiente ácido, e descolore na presença de dióxido de enxofre e ácido ascórbico (DOWNHAM; COLLINS, 2000). É utilizado na fabricação de bebidas, caramelos, confeitos e sorvetes (CALVO, 2006).

Quanto à sua toxicidade, há relatos na literatura que a indigotina pode causar náuseas, vômitos, hipertensão e ocasionalmente alergia, com prurido e problemas respiratórios (CUNHA, 1998; NETTO, 2009; PRADO; 2003), assim como hiperatividade e déficit de atenção em crianças (MCCANN et al., 2007). De acordo com o JECFA (2010) sua IDA é de 0-5 mg/kg de peso corpóreo (BRASIL, 2016).

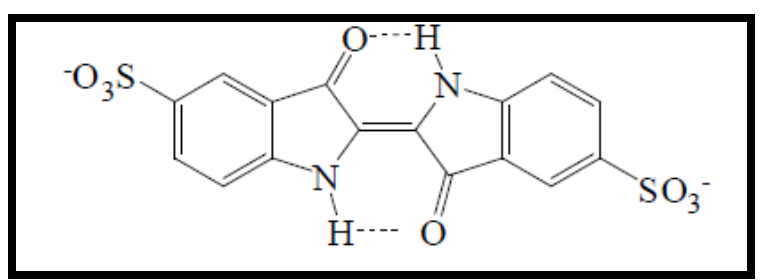

Figura 10. Estrutura química do corante indigotina.

Fonte: ISENMANN, 2014. 


\subsubsection{Azul brilhante (E133)}

O corante azul brilhante é sintetizado a partir da tinta do alcatrão de carvão e faz parte do grupo dos corantes trifenilmetanos. Consiste de um sal tri-sódico de 4',4"-di (N-etil3- sulfonatobenzil amino)-trifenil metil-2-sulfonato (Figura 11) (PRADO; GODOY, 2003). Possui moderada estabilidade à luz, calor e ácido e possui baixa estabilidade oxidativa. É utilizado em laticínios, balas, cereais, queijos, recheios, gelatinas, licores e refrescos (MCCANN et al., 2007).

Quanto à toxicologia, há relato de que o azul brilhante pode causar hiperatividade em crianças, eczema e asma, e também deve ser evitado por pessoas sensíveis às purinas (MCCANN et al., 2007). Estudos também demonstraram que o corante pode causar hipersensibilidade em indivíduos suscetíveis; citotoxicidade e genotoxidade observadas em culturas de células humanas in vitro e absorção pela mucosa oral, atingindo a corrente sanguínea (EFSA, 2010; KUS; EROGLU, 2015; LUCOVÁ et al., 2013). De acordo com o JECFA (2006) sua IDA é de 0-12,5 mg/kg de peso corpóreo (BRASIL, 2016).

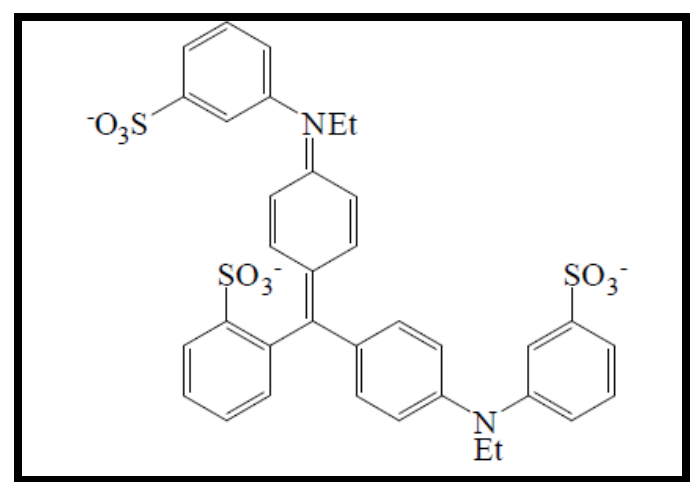

Figura 11. Estrutura química do corante azul brilhante.

Fonte: ISENMANN, 2014.

\subsubsection{Azul patente V (E131)}

O corante azul patente $V$ também é conhecido pelo nome de "azul de sulfano". É um corante usado para obter tons de verde nos alimentos, quando combinado com corantes amarelos como a tartrazina e o amarelo crepúsculo (CALVO, 2006). Seu nome químico consiste de um sal de cálcio di-4-[dietilamino ciclohexa-2,5-dienilideno(-4-dietilaminofenil) metil]-6- hidroxibenzeno -1,3-di-sulfonato (Figura 12) (PRADO; GODOY, 2003). Tem excelente estabilidade à luz, ácido e calor, mas apresenta descoloração na presença de ácido ascórbico e dióxido de enxofre. É utilizado em conservas de vegetais (cerejas verdes e ameixa, por exemplo), em pastelaria, doces e bebidas (CALVO, 2006).

Quanto à toxicologia, foi relatado haver absorção pela mucosa oral, atingindo a corrente sanguínea; efeito de redução nos valores de hemoglobina, hematócrito e contagens de glóbulos vermelhos após exposição crônica ao corante (LUCOVÁ et al., 2013; EFSA, 2013). Também foi indicado que pode causar alergias, urticária e câncer (CALVO, 2006). De acordo com o JECFA (2008) sua IDA é "não alocada" (BRASIL, 2016), ou seja, quando os dados toxicológicos disponíveis não são suficientes para se estabelecer a segurança de uso do mesmo (BRASIL, 2009). 


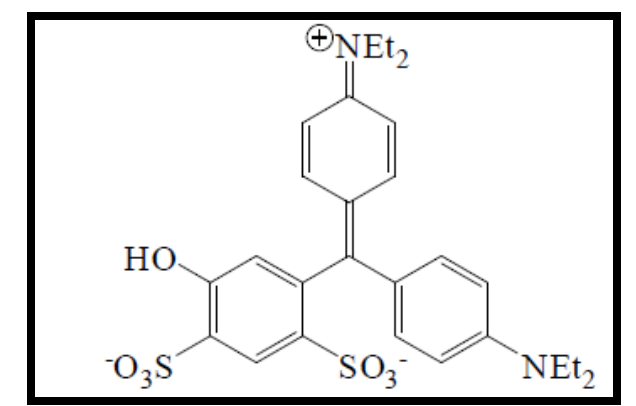

Figura 12. Estrutura química do corante azul patente $\mathrm{V}$.

Fonte: ISENMANN, 2014.

\subsubsection{Amarelo de quinoleína (E104)}

O corante amarelo de quinoleína é também conhecido como "amarelo de quinolina" ou "amarelo ácido 3". Esse corante é uma mistura de vários produtos químicos muito semelhantes entre si, diferindo no número e posição dos grupos sulfônicos no primeiro dos anéis aromáticos (CALVO, 2006). Quimicamente consiste em um sal dissódico do ácido 2(2-quinolil)-indanodiona-1,3-dis-sulfónico (Figura 13) (PRADO; GODOY, 2003). É usado em bebidas refrescantes e alcoólicas e na preparação de produtos de pastelaria, vegetais enlatados, derivados de carne ou peixe, entre outros (CALVO, 2006).

Quanto à toxicologia, foi relatado dermatite de contato, broncoespasmo e reação não imunológica (anafilactóide) (STEFANI et al., 2009). De acordo com o JECFA (2011) sua IDA é de 0-5 mg/kg de peso corpóreo (BRASIL, 2016).

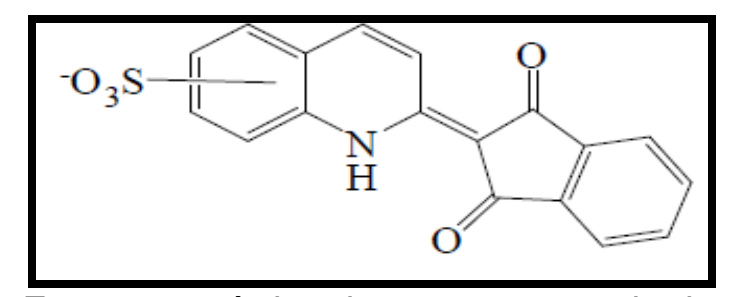

Figura 13. Estrutura química do corante amarelo de quinoleína.

Fonte: ISENMANN, 2014.

\subsubsection{Verde rápido (E143)}

O corante verde rápido faz parte do grupo trifenilmetanos, e seu nome químico consiste de um sal tri-sódico 4-[4-(N-etil-p- sulfobenzil amino) -fenil]-(4-hidroxi-2sulfofenil-metileno)- 1-(N-etil-N-p- sulfobenzil)- 2,5-ciclohexa dienimina (Figura 14) (PRADO; GODOY, 2003). Apresenta razoável estabilidade à luz, calor e ácido, mas possui baixa estabilidade oxidativa (DOWNHAM; COLLINS, 2000). É utilizado em bebidas à base de chá verde, balas e chicletes, mas há muitos alimentos de cor violeta (gelatinas, sucos, balas e gomas) que são feitos a partir da combinação desse corante com outros do grupo azo (BARROS; BARROS, 2010).

Quanto à toxicologia, foi capaz de induzir a inibição da atividade sináptica de interneurônios do hipocampo de ratos (VAN HOOFT, 2002), assim como apresentou efeito carcinogênico nas experiências realizadas por Lederer (1990). De acordo com o JECFA (2008) sua IDA é de 0-25 mg/kg de peso corpóreo (BRASIL, 2016). 


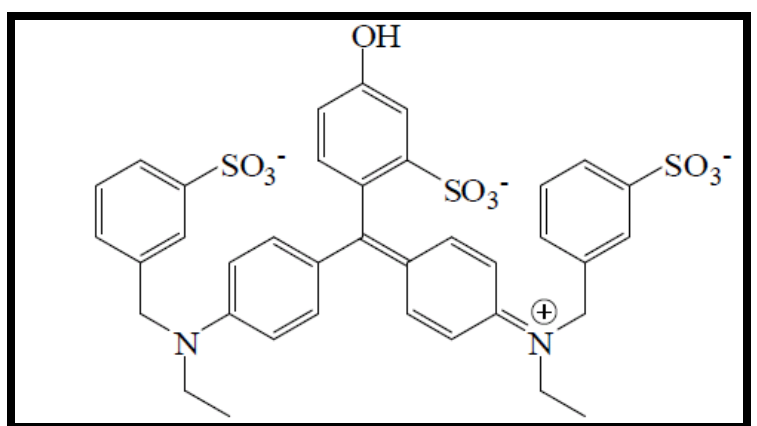

Figura 14. Estrutura química do corante verde rápido.

Fonte: ISENMANN, 2014.

\section{Considerações finais}

O uso de aditivos com função corante em alimentos e bebidas é importante do ponto de vista tecnológico, pois estão relacionados à qualidade, caracterização e tipificação do produto, influenciando diretamente à aceitação sensorial.

Após avaliar os resultados de pesquisas de diversos autores, pode-se concluir que alguns corantes, particularmente os artificiais, podem trazer efeitos adversos a longo prazo, com o desenvolvimento de enfermidades e ou outras complicações fisiológicas. Tais efeitos estão diretamente associados à quantidade e à frequência do consumo de alimentos contendo essas substâncias, cuja IDA (Ingestão Diária Aceitável) nem sempre está estabelecida.

A indústria de alimentos tem o desafio de atender à demanda de mercado quanto à cor, respeitando os valores estabelecidos pela legislação para estes aditivos, e contribuir para minimizar os efeitos adversos à saúde. Nesse sentido, vem buscando alternativas para que os corantes artificiais sejam substituídos pelos naturais, que não proporcionam riscos à saúde quando utilizados nas doses recomendadas, atendendo às crescentes exigências dos consumidores por produtos com apelo de saudabilidade. Os consumidores devem buscar informações fidedignas sobre os produtos que consomem, buscando não ingerir o mesmo aditivo através de vários produtos na dieta diária, evitando assim ultrapassar a IDA. Rótulos com informações claras e objetivas acerca da constituição do produto, incluindo os corantes, são fundamentais no entendimento e escolhas pelo consumidor.

\section{Referências}

ABDULLAH, S. U. et al. Binding ability of Allura Red with food proteins and its impact on protein digestibility. Food Chemistry, v. 110, n. 3, p. 605-610, 2008. https://doi.org/10.1016/j.foodchem.2008.02.049.

AL-SHABIB, N. A. et al. Synthetic food additive dye "Tartrazine" triggers amorphous aggregation in cationic myoglobin. International Journal of Biological $\begin{array}{lllll}\text { Macromolecules, } & \text { v. } & 98, & \text { p } & 277-286,\end{array}$ https://doi.org/10.1016/j.ijbiomac.2017.01.097.

AMCHOVA, P.; KOTOLOVA, H.; RUDA-KUCEROVA, J. Health safety issues of synthetic food colorants. Regulatory Toxicology and Pharmacology, v. 73, n. 3, p. 914-922, 2015. https://doi.org/10.1016/j.yrtph.2015.09.026. 
AMIN, K. A.; HAMEID II, H. A.; ELSTTAR, A. H. A. Effect of food azo dyes tartrazine and carmoisine on biochemical parameters related to renal, hepatic function and oxidative stress biomarkers in young male rats. Food and Chemical Toxicology, v. 48, n. 10, p. 2994-2999, 2010. https://doi.org/10.1016/j.fct.2010.07.039.

ARNOLD, L.; LOFTHOUSE, N.; HURT, E. Artificial food colors and attention-deficit/ hyperactivity symptoms: conclusions to dye for. Neurotherapeutics, v. 9, n. 3, p. 599609, 2012. https://doi.org/10.1007/s13311-012-0133-x.

ATASEVEN, N. et al. Genotoxicity of monosodium glutamate. Food and Chemical Toxicology, v. 91, p. 8-18, 2016. https://doi.org/10.1016/j.fct.2016.02.021.

AZAD, M. B. et al. Nonnutritive sweeteners and cardiometabolic health: a systematic review and meta-analysis of randomized controlled trials and prospective cohort studies. Canadian Medical Association Journal, v. 189, n. 8, p. E929-E939, 2017. https://doi.org/10.1503/cmaj.161390.

BAFANA, A.; DEVI, S.; CHAKRABARTI, T. Azo dyes: past, present and the future. Environmental Reviews, v. 19, n. NA, p. 350-370, 2011. https://doi.org/10.1139/a11018.

BARROS, A. A.; BARROS, E. B. P. A Química dos Alimentos - Produtos fermentados e corantes. Coleção Química no Cotidiano, volume 4. Sociedade Brasileira de Química. São Paulo, 2010. p.85.

BASTAKI, M. et al. Lack of genotoxicity in vivo for food color additive Allura Red AC. Food and Chemical Toxicology, v. 105, p. 308-314, 2017. https://doi.org/10.1016/j.fct.2017.04.037.

BASU, A.; KUMAR, G. S. Study on the interaction of the toxic food additive carmoisine with serum albumins: A microcalorimetric investigation. Journal of Hazardous Materials, v. 273, p. 200-206, 2014. https://doi.org/10.1016/j.jhazmat.2014.03.049.

BASU, A.; KUMAR, G. S. Binding of carmoisine, a food colorant, with hemoglobin: Spectroscopic and calorimetric studies. Food Research International, v. 72, p. 54-61, 2015. https://doi.org/10.1016/j.foodres.2015.03.015.

BAWAZIR, A. E. Effect of chocolate brown HT with olive oil on some neurotransmitters in different brain regions, physiological and histological structure of liver and kidney of male albino rats. Journal of Evolutionary Biology Research, v. 4. n. 1, p. 13-23, 2012. https://doi.org/10.5897/JEBR12.001.

BENTO, W. D. S.; LIMA, B. P.; PALM, A. P. S. Simultaneous determination of synthetic colorants in yogurt by HPLC. Food Chemistry, v. 183, p. 154-160, 2015. https://doi.org/10.1016/j.foodchem.2015.03.050.

BETTINI, S. et al. Food-grade TiO2 impairs intestinal and systemic immune homeostasis, initiates preneoplastic lesions and promotes aberrant crypt development in the rat colon. Scientific Reports, v. 7, p. 40373, 2017. https://doi.org/10.1038/srep40373.

BRASIL. Decreto $n^{\circ}$ 55.871, de 26 de março de 1965 . Normas reguladoras do emprego de aditivos para alimentos. Brasília: Presidência da República, 1965. Disponível em: https://www.gov.br/agricultura/pt-br/assuntos/vigilancia- 
agropecuaria/ivegetal/bebidas-arquivos/decreto-no-55-871-de-26-de-marco-de1965.doc/view. Acesso em: 20 maio de 2020.

Resolução - CNNPA no 44 de 1977a. Considera corante a substância ou a mistura de substâncias que possuem a propriedade de conferir ou intensificar a coloração de alimento (e bebida). Brasília: Presidência da República, 1977. Disponível em:

http://portal.anvisa.gov.br/documents/33916/391619/RESOLUCAO_CNNPA_44_1977. pdf/b8d43a0d-5c1b-4be1-ba69-67f69cf55446. Acesso em: 26 junho 2020.

Resolução CNNPA n 17, de 9 de maio de 1977b. Critérios para autorização de uso de coadjuvantes da tecnologia de fabricação e demais aditivos intencionais de alimentos, fixando os respectivos limites de adição e aprovar outras medidas para avaliação e emprego dos mesmos aditivos. Brasília: Presidência da República, 1977. Disponível em: http://portal.anvisa.gov.br/documents/33916/391619/Resolu\%25C3\%25A7\%25C3\%25 A30\%2BCNNPA\%2B17_1977.pdf/1cc01edb-b498-44e1-8f55-1a5a1f1820c3. Acesso em: 20 maio de 2020.

Resolução $n^{\circ} 37$ de $1977 c$. Considera laca o sal preparado a partir do corante incluído na Tabela I, anexa ao Decreto $n^{\circ}$ 55871/65, em combinação com o radical básico de alumínio ou cálcio. Disponível em: http://portal.anvisa.gov.br/documents/33916/391619/RESOLUCAO_37_77.pdf/81b4aef c-3a97-47c6-9622-33b48a6a8e32. Acesso em: 25 maio 2020.

. Resolução - CNNPA no 11 de 1978. Altera a Resolução - CNNPA n 44, de 1977. Brasília: Presidência da República, 1988. Disponível em: http://portal.anvisa.gov.br/documents/33916/391619/Resolucao_CNNPA\%2B_11_197 8.pdf/e846657e-d8cf-4f00-a2d6-ec0aa1a03a20. Acesso em: 28 maio 2020.

Resolução CNS/MS $n^{\circ}$ 04, de 24 de novembro de 1988. Aditivos Intencionais. Brasília: Presidência da República, 1988. Disponível em: http://portal.anvisa.gov.br/documents/33916/391619/Resolucao_04_1988.pdf/7311a4d 9-d5db-44d6-adbd-c7e6891d079d. Acesso em: 25 maio 2020.

Portaria $n^{\circ}$ 540, de 27 de outubro de 1997. Regulamento Técnico de Aditivos Alimentares. Brasília: Presidência da República, 1997. Disponível em: http://bvsms.saude.gov.br/bvs/saudelegis/svs1/1997/prt0540_27_10_1997.html. Acesso em: 20 maio de 2020.

Resolução $n^{\circ}$ 387, de 05 de agosto de 1999. Regulamento técnico que aprova o uso de Aditivos Alimentares, estabelecendo suas Funções e seus Limites Máximos para a Categoria de Alimentos 5: Balas, Confeitos, Bombons, Chocolates e Similares. Brasília: Presidência da República. Disponível em: http://portal.anvisa.gov.br/documents/33916/388729/Microsoft\%2BWord\%2B\%2BResolu\%25C3\%25A7\%25C3\%25A30\%2Bn\%25C2\%25BA\%2B387\%2Bde\%2B05 \%2Bde\%2Bagosto\%2Bde\%2B1999.pdf/1240800a-0d4b-4cc9-8d9c-5211e9c3fb93.

Acesso em: 04 junho 2020.

Resolução - RDC $n^{\circ}$ 259, de 20 de setembro de 2002. Regulamento técnico para rotulagem de alimentos embalados. Brasília: Presidência da República, 2002. Disponível em: https://files.cercomp.ufg.br/weby/up/912/o/resoluo_rdc_n_259_2002_rotulagem_em_geral.pdf. Acesso em: 24 maio de 2020 . 
Resolução RDC $n^{\circ}$ 25, de 15 de fevereiro de 2005. Regulamento técnico que aprova o uso dos Aditivos alimentares, estabelecendo suas funções e limites máximos para a categoria de alimentos: produtos protéicos - subcategoria: bebidas não alcoólicas a base de soja. Brasília: Presidência da República, 2005. Disponível em: $\quad$ http://portal.anvisa.gov.br/documents/33916/388729/Microsoft\%2BWord\%2B\%2BRDC\%2Bn\%25C2\%25BA\%2B25\%2Bde\%2B15\%2Bde\%2Bfevereiro\%2Bde\%2B2 005.pdf/f98bf7c0-e6cb-4e28-a0a5-299ebacb8e4e. Acesso em: 04 junho 2020.

Informe Técnico $\mathbf{n}^{\circ} \mathbf{3 0}$, de 24 de julho de 2007. Considerações sobre o corante amarelo tartrazina. Brasília: Presidência da República. Disponível em: http://portal.anvisa.gov.br/documents/33916/388729/Informe+T\%C3\%A9cnico+n\%C2 $\% \mathrm{BA}+30 \% 2 \mathrm{C}+\mathrm{de}+24+$ de+julho+de+2007/d47a1fea-fd03-4e94-8dff-fd87d3b1296a. Acesso em: 30 junho 2020.

Guia de procedimentos para pedidos de inclusão e extensão de uso de Aditivos alimentares e coadjuvantes de tecnologia de fabricação na Legislação brasileira. 2009. Agência Nacional de Vigilância Sanitária. Brasília: Presidência da República.

Disponível em: http://portal.anvisa.gov.br/documents/33916/417403/guia_pedidos.pdf/1802c8e3-6cba4a16-a28f-3bf6b591b1f5. Acesso em: 30 maio 2020.

RDC $n^{\circ}$ 45, de 03 de novembro de 2010. Dispõe sobre aditivos alimentares autorizados para uso segundo as Boas Práticas de Fabricação (BPF). Brasília: Presidência da República. Disponível em: http://portal.anvisa.gov.br/documents/10181/2718376/RDC_45_2010_COMP.pdf/19fb7 6e1-e1f8-48dd-a917-223c758af430. Acesso em: 30 junho 2020.

Ingestão Diária Aceitável - Corantes Alimentícios, 2016. Brasília: Presidência da República, 2016. Disponível em: http://portal.anvisa.gov.br/documents/219201/219401/Comp\%25C3\%25AAndio\%2B \%2BJaneiro\%2B2016_.pdf/eff5c6d9-b910-4915-bfd8-bbeeda6dffc2. Acesso em: 28 maio 2020.

CALVO, M. Colorantes Artificiales. Bioquímica de los alimentos. 2006. Disponível em: milksci.unizar.es/bioquimica/temas/aditivos/colorartif.html. Acesso em: 20 junho 2020.

CHAKRABORTY, S. P. Patho-physiological and toxicological aspects of monosodium glutamate. Toxicology Mechanisms and Methods, v. 29, n. 6, p. 389-396, 2019. https://doi.org/10.1080/15376516.2018.1528649.

CHEMIN C.; MILITO F. Transtornos alimentares em adolescentes. Revista Brasileira de Obesidade, Nutrição e Emagrecimento, v. 1, n. 2, p. 84-8, 2007.

CHUNG, K. T. Azo dyes and human health: a review. Journal of Environmental Science and Health, v. 34, n. 4, p. 233-261, 2016. https://doi.org/10.1080/10590501.2016.1236602.

CLYDESDALE, F. M. Color as a factor in food choice, Reviews in Food Science and Nutrition, v. 33, n. 1, p. 83-101, 1993. https://doi.org/10.1080/10408399309527614.

CONSTANT, P. B. L.; STRINGHETA, P. C.; SANDI, D. Corantes Alimentícios. Boletim do Centro de Pesquisa e Processamento de Alimentos, v. 20, n. 2, p. 203-220, 2002. http://dx.doi.org/10.5380/cep.v20i2.1248. 
COSENTINO, H. M. Efeitos da radiação ionizante em corantes naturais de uso alimentício. Orientadora: Nélida Lúcia Del Mastro. 2005. 149f. Tese (Doutorado em Ciências na Área de Tecnologia Nuclear - Aplicações). Instituto De Pesquisas Energéticas E Nucleares - IPEN/CNEN/SP, Autarquia Associada À Universidade De São Paulo, São Paulo, 2005.

CUNHA, M. R. Identificação e Qualidade de Corantes Sintéticos em Vários tipos de Balas Importadas. 1998. Disponível em: http://www.funed.mg.gov.br. Acesso em: 24 julho 2020.

CUNHA, F. G. Estudo da Extração Mecânica de Bixina das Sementes de Urucum em Leito de Jorro. Orientador: Marcos Antonio de Souza Barroso. 2008. 92f. Dissertação (Mestre em Engenharia Química), Faculdade de Engenharia Química, Universidade Federal de Uberlândia, Uberlândia, 2008.

DOWNHAM, A.; COLLINS, P. Colouring our food in the last and next millennium. International Journal of Food Science \& Technology, v. 35, n. 1, p. 5-22, 2000. https://doi.org/10.1046/j.1365-2621.2000.00373.x.

DWIVEDI, K.; KUMAR, G. Genetic damage induced by a food coloring dye (sunset yellow) on meristematic cells of Brassica campestris $L$. Journal of environmental and public health, v. 2015, n. 319727, p.1-5, 2015. https://doi.org/10.1155/2015/319727.

EFSA. European Food Safety Authority. Panel on Food Additives and Nutrient Sources added to Food (ANS); Scientific Opinion on the re-evaluation of Litholrubine BK (E 180) as a food additive. European Food Safety Authority Journal, v. 8, n. 5, p. 15861612, 2010.

Scientific Opinion on the re-evaluation of Patent Blue $V(E 131)$ as a food additive. European Food Safety Authority Journal, v.11, n. 3, p. 35, 2013.

ESMAEILI, S. et al. Degradation products of the artificial azo dye, Allura red, inhibit esterase activity of carbonic anhydrase II: A basic in vitro study on the food safety of the colorant in terms of enzyme inhibition. Food Chemistry, v. 213, p. 494-504, 2016. https://doi.org/10.1016/j.foodchem.2016.06.078.

ETEMADI, A. et al. Mortality from different causes associated with meat, heme iron, nitrates, and nitrites in the NIH-AARP Diet and Health Study: population based cohort study. British Medical Journal, v. 357, n. j1957, p. 1-30, 2017. https://doi.org/10.1136/bmj.j1957.

FEKETEA, G.; TSABOURI, S. Common food colorants and allergic reactions in children: Myth or reality? Food Chemistry, v. 230, p. 578-588, 2017. https://doi.org/10.1016/j.foodchem.2017.03.043.

FREITAS, A. S. Tartrazina: uma revisão das propriedades e análises de quantificação. Acta Tecnológica, v. 7, n. 2, p. 65-72, 2012.

GARCIA-SEGURA, S. et al. Solar photoelectrocatalytic degradation of Acid Orange 7 azo dye using a highly stable TiO 2 photoanode synthesized by atmospheric plasma spray. Applied Catalysis B: Environmental, v. 132-133, n.p. 142-150, 2013. https://doi.org/10.1016/j.apcatb.2012.11.037.

GHASEMPOUR, Z. et al. Synthesis of a molecularly imprinted polymer for the selective recognition of carmoisine (Azorubin E122) from pomegranate juice. Journal of 
$\begin{array}{lllllll}\text { Separation Science, } & \text { v. } 40, \quad \text { n. } & 4, & \text { p. } & 962-970,\end{array}$ https://doi.org/10.1002/jssc.201600855.

GOMEZ, M. et al. Determination of Sudan I in drinks containing Sunset yellow by adsorptive stripping voltammetry. Food chemistry, v. 212, p. 807-813, 2016. https://doi.org/10.1016/j.foodchem.2016.05.183.

GUIMARÃES, N. M. C. P. Perturbação de Hiperatividade e Défice de Atenção para além da genética. Orientador: José Manuel de Carvalho Tojal Monteiro. 2010. 31f. Dissertação (Mestrado Integrado em Medicina) Universidade do Porto, Porto, 2010.

HASHEM, M. M. et al. Immunological studies on Amaranth, Sunset Yellow and Curcumin as food colouring agents in albino rats. Food and Chemical Toxicology, v. 48, n. 6, p. 1581-1586, 2010. https://doi.org/10.1016/j.fct.2010.03.028.

HONG, M. N. et al. Improved analytical method of synthetic food colour additive, Brown HT by high-performance liquid chromatography. Agriculture \& Food, v. 2, p. 68-75, 2014.

HONORATO, T. C. et al. Aditivos alimentares: aplicações e toxicologia. Revista Verde de Agroecologia e Desenvolvimento Sustentável, v. 8, n. 5, p. 01-11, 2013.

ISENMANN, A. F. Corantes. Timóteo, MG. $2^{\text {a }}$ ed. 2014, 440 p.

JIANG, S. et al. A novel molecularly imprinted sensor for direct tartrazine detection. $\begin{array}{lllllll}\text { Analytical Letters, } & \text { v. } 47, \quad \text { n. } 2, & \text { p. }\end{array}$ https://doi.org/10.1080/00032719.2013.834442.

JOINT FAO/WHO EXPERT COMMITTEE ON FOOD ADDITIVES (JECFA) Compendium of food additive specifications. Food and Agriculture Organization of The United Nations. Rome, 2011. Disponível em: http://www.fao.org/3/a0691e/a0691e00.htm. Acesso em: 25 maio 2020.

KHATUN, A. et al. Chocolate brown HT impairs the function of the ovary by depressing the hypothalamic-hypophyseal-ovarian servomechanism in albino rat. International Journal of Pharma and Bio Sciences, v. 8, n. 3, p. 344-350, 2017. https://doi.org/10.22376/ijpbs.2017.8.3.b344-350.

KHODARAHMI, R.; ASHRAFI-KOOSHK, M. R.; KHALEDIAN, K. Allura Red, the artificial azo dye, inhibits esterase activity of carbonic anhydrase II: a preliminary study on the food safety in term of enzyme inhibition. Journal of Reports in Pharmaceutical Sciences, v. 4, n. 1, p. 43-52, 2015.

KOBYLEWSKI, S.; JACOBSON, M. F. Food dyes: A rainbow of risks. Center for Science in the Public Interest, Washington. p. 68. 2010. Disponível em:

https://cspinet.org/sites/default/files/attachment/food-dyes-rainbow-of-risks.pdf. Acesso em: 24 junho 2020.

KONIG, J. Food colour additives of synthetic origin. In: SCOTTER, Michael J. (Ed.). Colour Additives for Foods and Beverages. Cambridge: Woodhead Publishing, Cap 2, 2015. p. 35-60. 
KRAMER, N. I. et al. Characterizing the coverage of critical efects relevant in the safety evaluation of food additives by AOPs. Archives of Toxicology, v. 93, p. 2115-2125, 2019. https://doi.org/10.1007/s00204-019-02501-x.

KUS, E.; EROGLU, H. E. Genotoxic and cytotoxic effects of sunset yellow and brilliant blue, colorant food additives, on human blood lymphocytes. Pakistan Journal of Pharmaceutical Sciences, v. 28, n. 319727, p. 227-230, 2015.

LEDERER, J. Alimentação e câncer. ed: Manole Dois, São Paulo. 1990. 279p.

LEHMANN, G. et al. Rapid method for detection and identification of synthetic watersoluble coloring matter in food and drugs. Journal of Association of Official $\begin{array}{lllllll}\text { Analytical Chemists, } & \text { v. } 53, \quad \mathrm{n} \quad 6, \quad \text { p. } 1182-1189,\end{array}$ https://doi.org/10.1093/jaoac/53.6.1182.

LEO, L. et al. Occurrence of Azo Food Dyes and their Effects on Cellular Inflammatory Responses. Nutrition, v. 46, p. 36-40, 2017. https://doi.org/10.1016/j.nut.2017.08.010.

LI, X. Q. et al. Identification and determination of 34 water-soluble synthetic dyes in foodstuff by high performance liquid chromatography-diode array detection-ion trap time-of-flight tandem mass spectrometry. Food Chemistry, v. 182, p. 316-326, 2015. https://doi.org/10.1016/j.foodchem.2015.03.019.

LUCOVÁ, M. et al. Absorption of triphenylmethane dyes brilliant blue and patent blue through intact skin, shaven skin and lingual mucosa from daily life products. Food and Chemical Toxicology, v. 52, p.19-27, 2013. https://doi.org/10.1016/j.fct.2012.10.027.

MACIOSZEK, V. K.; KONONOWICZ, A. K. The evaluation of the genotoxicity of two commonly used food colors: Quinoline Yellow (E 104) and Brilliant Black BN (E 151). Cellular and Molecular Biology Letters, v. 9, n. 1, p. 107-122, 2004.

MARMITT, S.; PIROTTA, L.V.; STÜLP, S. Aplicação de fotólise direta e UV/H2O2 a efluente sintético contendo diferentes corantes alimentícios. Revista Química Nova, v. 33, n. 2, p. 384-8, 2010.

MARTÍNEZ SUÁREZ, J. F. Comportamiento electroquímico de colorantes antraquinónicos, azul de metileno, y compuestos afines en solución de solventes no-acuosos. Orientador: María Virginia Mirífico. 2017. 324f. Tese (Doutorado en Ciencias Exactas, Área Química), Facultad de Ciencias Exactas, Universidad Nacional de La Plata, Buenos Aires, 2017.

MARTINS, M. S. Uso de corantes artificiais em alimentos: Legislação brasileira. Aditivos \& Ingredientes. 2014.2 Disponível em: http://insumos.com.br/aditivos_e_ingredientes/materias/819.pdf. Acesso em: 25 maio 2020.

MASONE, D.; CHANFORAN, C. Study on the interaction of artificial and natural food colorants with human serum albumin: A computational point of view. Computational biology and chemistry, v. 56, p. 152-158, 2015. https://doi.org/10.1016/j.compbiolchem.2015.04.006.

MENDONÇA, J. N. Identificação e isolamento de corantes naturais produzidos por actinobactérias. Orientador: Luiz Alberto Beraldo de Moraes. 2011. $121 \mathrm{f}$. 
Dissertação (Mestrado em Ciências) - Faculdade de Filosofia, Ciências e Letras, Universidade de São Paulo, Ribeirão Preto, 2011.

MERCOSUL/GMC/RES. N 52/98. Regulamento técnico "critérios para determinar funções de aditivos, aditivos e seus limites máximos para todas as categorias de alimentos". $1998 . \quad$ Disponível em: http://www.inmetro.gov.br/barreirastecnicas/PDF/GMC_RES_1998-052.pdf. Acesso em: 30 junho 2020.

MERCOSUR/GMC/RES N ${ }^{\circ}$ 50/97. Reglamento tecnico asignacion de aditivos y su concentracion maxima para la categoria de alimentos 7: productos de panificacion $\quad \mathbf{y}$ galleteria. $1997 . \quad$ Disponível em: http://www.inmetro.gov.br/barreirastecnicas/PDF/GMC_RES_1997-050.pdf. Acesso em: 30 junho 2020.

MCCANN, D. et al. Food additives and hyperactive behaviour in 3-year-old and 8/9year-old children in the community: a randomised, double-blinded, placebo-controlled trial. Lancet, v. 370, n. 9598, p. 1560-1567, 2007. https://doi.org/10.1016/S01406736(07)61306-3.

MITTAL, A. et al. Process development for the removal and recovery of hazardous dye erythrosine from wastewater by waste materials - Bottom Ash and De-Oiled Soya as adsorbents. Journal of Hazardous Materials, v. 138, n. 1, p. 95-105, 2006. https://doi.org/10.1016/j.jhazmat.2006.05.038.

MOUBARAC, J. C. et al. Consumption of ultra-processed foods predicts diet quality in $\begin{array}{lllll}\text { Canada. } & \text { Appetite, } & \text { v. } & \text { 108, }\end{array}$ https://doi.org/10.1016/j.appet.2016.11.006.

MOUTINHO, I. L. S; BERTGES, L. C; ASSIS, R. V. C. Prolonged use of Food Dye Tartrazine and its Effects on the Gastric Mucosa of Wistar Rats. Brazilian Journal of Biology, v. $67, \quad$ n. $1, \quad$ p. 141-145, 2007. https://doi.org/10.1590/S151969842007000100019.

MPOUNTOUKAS, P. et al. Cytogenetic evaluation and DNA interaction studies of the food colorants amaranth, erythrosine and tartrazine. Food and Chemical Toxicology, v. 48, n. 10, p. 2934-2944, 2010. https://doi.org/10.1016/j.fct.2010.07.030.

NETTO, R. C. M. Dossiê corantes. Food Ingredients Brasil, n. 9, 2009. Disponível em:

https://revista-fi.com.br/upload_arquivos/201606/2016060213572001465326315.pdf.

Acesso em: 27 julho 2020.

PARMAR, R. S.; SINGH, C. A comprehensive study of eco-friendly natural pigment and its applications. Biochemistry and Biophysics Reports, v. 13, p. 22-26, 2018. https://doi.org/10.1016/j.bbrep.2017.11.002.

PASIAS, I. N.; ASIMAKOPOULOS, A. G.; THOMAIDIS, N. S. Food colours for bakery products,snack foods, dry soup mixes, and seasonings. In: SCOTTER, Michael J. (Ed.). Colour Additives for Foods and Beverages. Cambridge: Woodhead Publishing, Cap. 8. 2015, p. 211-226. https://doi.org/10.1016/B978-1-78242-0118.00008-8. 
POLÔNIO, M. L.T; PERES, F. Consumo de aditivos alimentares e efeitos à saúde: desafios para a saúde pública brasileira. Caderno de Saúde Pública, v. 25, n. 8, p. 1653-1666, 2009. https://doi.org/10.1590/S0102-311X2009000800002.

POLÔNIO, M. L. T. Percepção de mães quanto aos riscos à saúde de seus filhos em relação ao consumo de aditivos alimentares: o caso dos pré-escolares do Município de Mesquita. Orientador: Frederico Peres. 2010. 129f. Tese (Doutorado em Ciências na área de Saúde Pública e Meio Ambiente). Escola Nacional de Saúde Pública Sergio Arouca, Rio de Janeiro, 2010.

POURREZA, N.; RASTEGARZADEH, S.; LARKI, A. Determination of Allura red in food samples after cloud point extraction using mixed micelles. Food Chemistry, v. 126, n. 3, p. 1465-1469, 2011. https://doi.org/10.1016/j.foodchem.2010.11.158.

PRADO, M. A. Desenvolvimento e comparação de técnicas analíticas, cromatografia líquido de alta eficiência e eletroforese capilar, na determinação de corantes artificiais. Orientador: Helena Teixeira Godoy. 2003. 130f. Tese (Doutorado em ciências de alimentos) - Universidade Estadual de campinas, São Paulo, 2003.

PRADO, M. A.; GODOY, H. T. Corantes artificiais em alimentos. Alimentos e Nutrição, v. 14, n. 2, p. 237-250, 2003.

Teores de corantes artificiais em alimentos determinados por cromatografia líquida de alta eficiência. Revista Química Nova, v. 30, n. 2, p. 268-273, 2007.

QUIST, A. J. L. et al. Ingested nitrate and nitrite, disinfection by-products, and pancreatic cancer risk in postmenopausal women. International Journal of Cancer, v. 142, n. 2, p. 251-261, 2018. https://doi.org/10.1002/ijc.31055.

Rocío, J. S. La Quimica del Color en los Alimentos. Revista Química Viva, v. 12, n. 3, p. 234-246, diciem. 2013.

ROMIERO, S., DELGADO, M. Aditivos alimentares: conceitos básicos, legislação e controvérsias. Revista Nutrícias, n. 18, p. 22-26, 2013.

ROVINA, K. et al. Methods for the analysis of Sunset Yellow FCF (E110) in food and beverage products-a review. Trends in Analytical Chemistry, v. 85, p. 47-56, 2016. https://doi.org/10.1016/j.trac.2016.05.009.

SARIKAYA, R.; SELVI, M.; ERKOÇ, F. Evaluation of potential genotoxicity of five food dyes using the somatic mutation and recombination test. Chemosphere, v. 88, n. 8, p. 974-979, 2012. https://doi.org/10.1016/j.chemosphere.2012.03.032.

SASAKI, Y. F. et al. The comet assay with 8 mouse organs: results with 39 currently used food additives. Mutation Research/Genetic Toxicology and Environmental Mutagenesis, v. 519, n. 1-2, p.103-119, 2002. https://doi.org/10.1016/S13835718(02)00128-6.

SHIBAMOTO, T.; BJELDANES, L. F. Introdução à toxicologia de alimentos. 2 ed. Rio de Janeiro: Elsevier, 2014. 306 p. 
SHIMADA, C. et al. Differential colon DNA damage induced by azo food additives between rats and mice. The journal of toxicological sciences, v. 35 , n. 4, p. 547554, 2010. https://doi.org/10.2131/jts.35.547.

SMITH, T. J. S. et al. Caramel Color in Soft Drinks and Exposure to 4-Methylimidazole: A Quantitative Risk Assessment. PLoS One, v. 10, n. 2, p. e0118138, 2015. https://doi.org/10.1371/journal.pone.0118138.

SOFFRITTI, M. et al. Sucralose administered in feed, beginning prenatally through lifespan, induces hematopoietic neoplasias in male swiss mice. International Journal of Occupational and Environmental Health, v. 22, n. 1, p. 7-17, 2016. https://doi.org/10.1080/10773525.2015.1106075.

SPELLMEIER, J. G.; STÜLP, S. Avaliação da degradação e toxicidade dos corantes alimentícios eritrosina e carmim de cochonilha através de processo fotoquímico. Acta $\begin{array}{lllll}\text { Ambiental } \quad \text { Catarinens, } & \text { v.6, } & \text { p.1/2, } & \text { 65-83, }\end{array}$ https://doi.org/10.24021/raac.v6i1/2.431.

STEFANI, G. P. et al. Presença de corantes e lactose em medicamentos: avaliação de 181 produtos. Revista Brasileira de alergia e imunopatologia, v. 32, n. 1, p. 18-26, 2009.

SUN, B.; WANG, J. Food Additives. In: Food Safety in China: Science, Technology, Management and Regulation. China, 2017. p.186-200.

TANAKA, T. Reproductive and neurobehavioural toxicity study of erythrosine administered to mice in the diet. Food and Chemical Toxicology, v. 39, n. 5, p. 447454, 2001. https://doi.org/10.1016/s0278-6915(00)00163-0.

TOMASKA, L. D.; BROOKE-TAYLOR, S. Food Additives. In: MOTARJEMI, Y.; MOY, G.; TODD, E. (ed.). Encyclopedia of Food Safety, 1 ed. v. 2. Cambridge: Academic Press, 2014. p. 449-454.

TSUDA, S. et al. DNA damage induced by red food dyes orally administered to pregnant and male mice. Toxicological Sciences, v. 61, n. 1, p. 92-99, 2001. https://doi.org/10.1093/toxsci/61.1.92.

UYSAL, O. K.; ARAL, E. Teratogenic effects and the role in the etiology of atopic diseases of erythrosine (FD and C Red No. 3). Turkish Journal of Medical Sciences, v. 28, n. 4, p. 363-368, 1998.

YADAV, A. et al. Sunset yellow FCF, a permitted food dye, alters functional responses of splenocytes at non-cytotoxic dose. Toxicology Letters, v. 217, n. 3, p. 197-204, 2013. https://doi.org/10.1016/j.toxlet.2012.12.016.

YASSUNAKA, N. N. et al. Photodynamic Inactivation Mediated by Erythrosine and its Derivatives on Foodborne Pathogens and Spoilage Bacteria. Current Microbiology, v. 71, p. 243-251, 2015. https://doi.org/10.1007/s00284-015-0827-5.

WU, D. et al. Characterisation of interaction between food colourant allura red AC and human serum albumin: Multispectroscopic analyses and docking simulations. Food chemistry, v. 170, p. 423-429, 2015. https://doi.org/10.1016/j.foodchem.2014.08.088. 
VAN HOOFT, J. A. Fast green FCF (food green 3) inhibits synaptic activity in rat hippocampal interneurons. Neuroscience Letters, v. 318, n. 3, p. 163-165, 2002. https://doi.org/10.1016/S0304-3940(01)02452-1.

VIENNOIS, E. et al. Dietary Emulsifier-Induced Low-Grade Inflammation Promotes Colon Carcinogenesis. Journal of Cancer Research, v. 77, n. 1, p. 27-40, 2017. https://doi.org/10.1158/0008-5472.CAN-16-1359.

VIENNOIS, E.; CHASSAING, B. First victim, later aggressor: How the intestinal microbiota drives the pro-inflammatory effects of dietary emulsifiers? Gut Microbes, v. 9, n. 3, p. 289-291, 2018. https://doi.org/10.1080/19490976.2017.1421885.

ZHANG, J. et al. A fluorescence-quenching method for quantitative analysis of Ponceau 4R in beverage. Food Chemistry, v. 221, p. 803-808, 2017. https://doi.org/10.1016/j.foodchem.2016.11.100.

\section{Autores}

Josiane Bizzi Schlemmer Braun ${ }^{1, \star}$, Rosane da Silva Rodrigues ${ }^{2}$

1. Curso de Pós-Graduação Lato Sensu em Ciência dos Alimentos, Centro de Ciências Químicas, Farmacêuticas e de Alimentos, Universidade Federal de Pelotas, Campus Capão do Leão, Caixa Postal 354, CEP. 96010-900, Pelotas, RS, Brasil; Faculdade Metodista Centenário, R. Dr. Turi, 2003 - Centro, Cep 97050.180, Santa Maria, RS.

2. Centro de Ciências Químicas, Farmacêuticas e de Alimentos, Universidade Federal de Pelotas, Campus Capão do Leão, Caixa Postal 354, CEP. 96010-900, Pelotas, RS, Brasil

* Autor para correspondência: jobizzi@yahoo.com.br 